\title{
Response of Soil Water and Wheat Yield to Rainfall and Temperature Change on the Loess Plateau, China
}

\author{
Xuechun Wang ${ }^{1}$, Muslim Qadir ${ }^{1,2}$, Fahd Rasul ${ }^{3,4} \mathbb{C}^{\mathbb{D}}$, Guotao Yang ${ }^{1}$ and Yungao $\mathrm{Hu}{ }^{1, *}$ \\ 1 School of Life Science and Engineering, Southwest University of Science and Technology, Mianyang 621000, \\ China; xuechunwang@swust.edu.cn (X.W.); msmirwani22@gmail.com (M.Q.); langzi0509@sina.com (G.Y.) \\ 2 Faculty of Agriculture, Lasbela University of Agriculture, Water and Marine Sciences Uthal, \\ Balochistan 74200, Pakistan \\ 3 Agweathernet, Washington State University, Prosser, DC 99350, USA; drfahdrasul@gmail.com \\ 4 AgroClimatology Lab, Department of Agronomy, University of Agriculture, Faisalabad 38000, Pakistan \\ * Correspondence: hongni2005@sohu.com; Tel.: +86-081-6608-9529
}

Received: 5 May 2018; Accepted: 21 June 2018; Published: 27 June 2018

check for updates

\begin{abstract}
Understanding the influences of rainfall and temperature on soil water and the grain production of winter wheat (Triticum aestivum L.), is of great importance to ensure the sustainability of food production on the Loess Plateau of China. Based on calibration and evaluation, the Environmental Policy Integrated Climate (EPIC) model was employed to determine the response of soil water and winter wheat to rainfall and temperature changing over the last 30 years in different regions. Results showed that (1) the EPIC model simulated soil water content well in 0-2 m soil, with a relative root mean square error (RRMSE) value of $6.0 \sim 14.0 \%$, and the mean value of $R^{2}$ was 0.824 , which was similar to the value of ME (0.815); (2) rainfall decreased 13.6-24.9\% more from 2001 to 2010 than it did during 1961-2000, while its minimum and maximum temperature increased 1.00-1.55 ${ }^{\circ} \mathrm{C}$ and $0.30-0.84{ }^{\circ} \mathrm{C}$ respectively, in comparison with 1961-2000; (3) both the increase of maximum temperature and the decrease of rainfall were harmful to the production of winter wheat. Contrarily, the increase of minimum temperature was beneficial to the production of winter wheat on the Loess Plateau of China. Furthermore, due to rainfall decreasing, the winter wheat yield of Luochuan, Changwu, Yuncheng, and Yan'an decreased by 8.5\%, 7.6\%, 11.7\%, and 12.3\%, respectively. Because of the rising of the maximum temperature, winter wheat yield decreased $6.4 \%, 6.8 \%, 7.2 \%$, and $-3.0 \%$, respectively. On the other hand, the increase of the minimum temperature raised the winter wheat yield of $8.8 \%, 10.2 \%, 1.5 \%$, and $12.0 \%$, respectively. Climate change, either precipitation reduction or temperature increase, decreased soil water in the dry land winter wheat field. Therefore, more water-saving technologies are needed to adapt to climate change, to store and use water sources more effectively in semi-arid regions. Though precipitation reduction and maximum temperature increase produced negative impacts on winter wheat yield, the uptrend in minimum temperature is better for increasing the winter wheat yield, which can be used by farmers and governments to adapt to climate change, by adjusting planting time properly.
\end{abstract}

Keywords: the Loess Plateau; climate change; EPIC model; semi-arid region

\section{Introduction}

Soil water is a major component of agricultural water resources, particularly in semiarid regions [1]. The Loess Plateau, one of the famous semiarid regions in the world, does not have enough rainfall water to support winter wheat (Triticum aestivum L.) growth during the growing season [2]. Besides a few outside and rocky mountains, most places on the Loess Plateau are covered by loess soil, whose thickness ranges from 50 to $100 \mathrm{~m}$ [3], suggesting that significant soil water 
recharge generally does not occur beyond 2-3 m; however, in rainy years, the infiltrating depth of rainwater may exceed 2 or even $3 \mathrm{~m}$. The water accumulates and is stored in the deep soil, which works as a water reservoir, providing enough water for crops during the dry season and insurance for sustainable food production on the Loess Plateau.

According to weather conditions and soil characteristics, agricultural scientists have suggested saving rainfall water in the deep soil and using deep soil water effectively for winter wheat production on the Loess Plateau $[4,5]$. With the development of water saving technologies, such as straw and film mulching, more and more rainfall water has been stored in deep soil $[4,5]$ in a semiarid region. By changing fertilizer management and the cropping system, agricultural scientists have increased water-use efficiency significantly in the winter wheat cropping system during last 20 years [6,7]. As an outcome of these technologies, winter wheat yield has increased significantly on the Loess Plateau of China during the last 20 years [8].

As part of the course of global climate change, rainfall and temperature have significantly changed on the Loess Plateau of China over the last 20 years. Related research shows that temperature on the Loess Plateau has increased $0.035-0.050{ }^{\circ} \mathrm{C}$ in the past year; its increasing rate is higher than the mean value for China overall [6,9]. Rainfall on the Loess Plateau, though, has followed a downward trend, though its decreasing rate is also higher than the mean value for China overall $[8,10]$. By analyzing meteorological data from 1971 to 2000, Wan et al. [11] reported that temperature had an upward trend, especially during winter and spring seasons, and the region's frost-free period extended 5-10 days at the Longdong area of the Loess Plateau. Yan et al. [12] reported that the increasing rate of temperature was $0.045{ }^{\circ} \mathrm{C}$ per year in the gully and hilly region of northern Shaanxi Province, which was higher than the mean value for the temperature increase in China overall. In the gully and hilly region of Shaanxi Province, the increasing rate of temperature was highest during the winter, and the decreasing rate of rainfall was highest during the summer.

It is certain that temperature and precipitation changing will lead to the change in soil water and winter wheat yield [12,13]. Tesfaye et al. [13] report that temperature increase and rainfall decrease together cause the decrease of soil water in a winter wheat field during the spring season in the highlands of northern Ethiopia. Er et al. [14] studied the impacts of climate change on agricultural production and ecological environment. Their results show that the increase of solar radiation and effective temperature result in the increase of water demand during the winter wheat growth period, and also delayed the breeding period by 1-3 days but brought the harvest season forward 1-2 days; therefore, the growth season of winter wheat shortened by 3-5 days, and the yield of winter wheat deceased $50-100 \%$. Though these studies clarify the impacts of climate change on winter wheat production in semiarid regions and on the Loess Plateau, the impacts of climate change on soil water are still not so clear in a semiarid region.

The objectives of this paper were to research the change of rainfall and temperature on the Loess Plateau of China, based on the analysis of weather data from 1961 to 2010, and to investigate the impacts of climate change on soil water and winter wheat yield, based on simulation results of the Environmental Policy Integrated Climate (EPIC) model. This study can provide some references for the farmers regarding how to adapt to changing to the climate and to produce winter wheat more sustainably in a semi-arid region.

\section{Materials and Methods}

\subsection{Environmental Policy Integrated Climate Model and Field Experiment}

Williams et al. $[15,16]$ built the EPIC model at Black Land Research Center in America during the 1980s. The EPIC model contains more than six sub-models, such as soil, meteorology, and crop growth models. It can calculate crop growth considering the impacts of soil water, soil nutrition, rainfall, and temperature by day time step [17]. The original objective of building the EPIC model was to evaluate the impacts of soil and water verification on agricultural food production [15]. 
Stockle et al. $[18,19]$ improved the sub-model of crop growth, and made the EPIC model calculate the impacts of $\mathrm{CO}_{2}$ content and atmospheric pressure on crop transpiration efficiency and solar energy conversion efficiency. Izaurralde et al. [20] improved the carbon cycle in the EPIC model, and let it calculate the impacts of climate change on agricultural production. WinEPIC V6 is the most recent version of the EPIC model. It can simulate soil water and crop yield well, and is one of the effective tools to simulate the impacts of climate change on cropping systems.

Long term experimental data (1986-2000) for winter wheat at Changwu Agricultural and Ecological Station was used to calibrate and evaluate the EPIC model. When the experiment started, soil organic matter content was $10.5 \mathrm{mg} / \mathrm{kg}$, with a nitrogen content of $37.0 \mathrm{mg} / \mathrm{kg}$; the phosphorus content was $4.6 \mathrm{mg} / \mathrm{kg}$, and potassium content was $129.3 \mathrm{mg} / \mathrm{kg}$. Winter wheat was planted in September with a seed concentration of $163 \mathrm{~kg} / \mathrm{hm}^{2}$ and harvested at the middle of June. Fertilizer used for winter wheat was $120 \mathrm{~kg} / \mathrm{hm}^{2} \mathrm{~N}$ and $60 \mathrm{~kg} / \mathrm{hm}^{2} \mathrm{P}_{2} \mathrm{O}_{5}$; in addition, $60 \mathrm{~kg} / \mathrm{hm}{ }^{2}$ manure whose organic matter content was $44.29 \mathrm{~kg} / \mathrm{hm}^{2}$ was used for the winter wheat. Daily meteorological data used in the EPIC model collected from Changwu meteorological station, which was $1000 \mathrm{~m}$ distance from Changwu Agricultural and Ecological Station. Soil samples were taken on the 20th day of each month by the core break method [21] and measured by the oven-drying method [22].

\subsection{Research Design}

To clarify the impacts of precipitation and temperature change on wheat yield and soil moisture in winter wheat field, this study used elements replaced methods to set three climate scenarios during 1961-2010.: A, a change precipitation only, (TR1); B: a change maximum temperature only (TR2); C: a change minimum temperature only, (TR3). Every 10 years the EPIC model will be run with the initial soil conditions, same crop and management parameters, and printout the simulation results of soil moisture and winter wheat yield, respectively. Luochuan, Changwu, Yuncheng and Yan'an, in this study, are the representative of humid area, sub-humid area, semi-arid area, and arid areas on the Loess Plateau of China, respectively.

\subsection{Statistical Methods}

Available soil moisture (ASW) calculated by Equation (1):

$$
A S W=\sum_{i=1}^{n}((S W i-W P i) \times P i \times H i \times 10)
$$

ASW was available in soil water in 0-4.0 m soil (mm), ASWi was available soil water in soil layer $i$ $(\mathrm{mm}), n$ was the maximum number of the measured soil layer, $S W i$ was the soil water content for soil layer $i(\%), W P i$ was the wilting point for soil layer $i(\%), P i$ was the bulk density for the soil layer $i$ $\left(\mathrm{g} / \mathrm{cm}^{3}\right)$, and $H i$ was thickness for soil layer $i(\mathrm{~cm})$.

Some statistical methods, such as RMSE, RRMSE, ME, RE, $R$, and $R^{2}$, were used to calibrate and evaluate the EPIC model.

$$
\begin{gathered}
R M S E=\left[\frac{1}{n} \sum_{i=1}^{n}(S i-M i)^{2}\right]^{\frac{1}{2}} \\
R R M S E=\frac{\left[\frac{1}{n} \sum_{i=1}^{n}(S i-M i)^{2}\right]^{\frac{1}{2}}}{\frac{1}{n \sum_{i=1}^{n} M i}} \times 100 \\
M E=1-\frac{\sum_{i=1}^{n}(S i-M i)^{2}}{\sum_{i=1}^{n}(S i-\overline{M i})^{2}} \\
R E(\%)=\frac{1}{n} \sum_{i=1}^{n} \frac{S i-M i}{M i} \times 100
\end{gathered}
$$




$$
\begin{gathered}
R=\frac{\sum((S i-\bar{S}) \times(M i-\bar{M}))}{\left[\sum((S i-\bar{S}) \times(M i-\bar{M}))\right]^{\frac{1}{2}}} \\
R^{2}=\frac{\left[\sum((S i-\bar{S}) \times(M i-\bar{M}))\right]^{2}}{\sum(S i-\bar{S})^{2} \times \sum(M i-\bar{M})^{2}}
\end{gathered}
$$

where RMSE was the root mean square error, RRMSE was the relative root mean square error, $M E$ was the model efficiency, $R E$ was the relative error, $R$ was the correlation coefficient, $R^{2}$ was the coefficient of determination, Si represents the simulated values, $\bar{S}$ was the average value for the simulated values, $M i$ was the measured values, and $\bar{M}$ was average value of the measured values.

Changes in precipitation and temperature calculated by Equations (8)-(10).

$$
\begin{gathered}
V c=\frac{\sqrt{\frac{1}{n} \sum\left(X_{i}-\bar{X}\right)^{2}}}{\bar{X}} \\
V a=\frac{\sum\left|X_{i}-\bar{X}\right|}{n} \\
V r=\frac{\sum\left|X_{i}-\bar{X}\right|}{n \times \bar{X}}
\end{gathered}
$$

where, $V c$ was the coefficient of variation, $V a$ absolute variability, $V r$ relative variability, $n$ number of samples, $X_{i}$ observed value, and $\bar{X}$ average value for observed. $V c$ estimates the severity of climatic change on the Loess Plateau, $V a$ and $V r$ reflect the annual variability of precipitation and temperature.

\section{Results}

\subsection{Changes in Precipitation and Temperature on the Loess Plateau from 1961-2010}

During the period 1961-2010, average annual rainfall on the Loess Plateau showed a volatilite downward trend (Figure 1: Rain), while the maximum temperature (Figure 1: Tmax) and minimum temperature (Figure 1: Tmin) showed a volatile upward trend.

From 2001-2010, mean annual precipitation at Luochuan, Changwu, Yuncheng, and Yan'an was $541,532,464$, and $393 \mathrm{~mm}$, respectively, which decreased $18.1 \%, 13.6 \%, 18.8 \%$, and $24.9 \%$, respectively, compared with 1961-1970. The regions' mean annual maximum temperatures were 15.89, 15.81, 19.96, and $9.72{ }^{\circ} \mathrm{C}$, respectively, during $2001-2010$, which increased $0.84,0.70,0.30$, and $0.90{ }^{\circ} \mathrm{C}$ respectively compared to 1961-1970. The mean annual minimum temperatures in Luochuan, Changwu, Yuncheng, and Yan'an were, respectively, 5.26, 4.44, 6.82, and $3.99^{\circ} \mathrm{C}$ from 2001-2010, which increased 1.00, 1.37, 1.55 , and $1.14^{\circ} \mathrm{C}$, respectively, compared to $1961-1970$.

Compared with 1961-1970, the $V r$ value of precipitation at Luochuan, Changwu, Yuncheng, and Yan'an decreased $0.039,0.013,0.021$, and 0.011 , respectively; their $V a$ values dropped 11.50, 2.16, 6.76 , and $4.12 \mathrm{~mm}$, respectively; their $V c$ values increased $0.029,0.087,0.020$, and 0.057 , respectively, during the 2001-2010 period. In comparison with 1961-1970, the $V r$ values for maximum temperature increased $0.012,0.005,0.003$, and 0.008 , respectively; their $V a$ values increased by $0.034,0.054,0.130$, and $0.100{ }^{\circ} \mathrm{C}$; their $V c$ values increased respectively by $0.019,0.006,0.001$, and 0.006 during 2001-2010. Compared with 1961-1970, the $V r$ values for maximum temperature in Luochuan, Changwu, Yuncheng, and Yan'an increased $0.045,0.035,0.009$, and 0.002 , respectively. Their $V a$ values increased by 0.115 , $0.106,0.172$, and $0.037^{\circ} \mathrm{C}$, while their $V c$ values increased $0.043,0.031,0.030$, and 0.030 respectively during 2001-2010. 


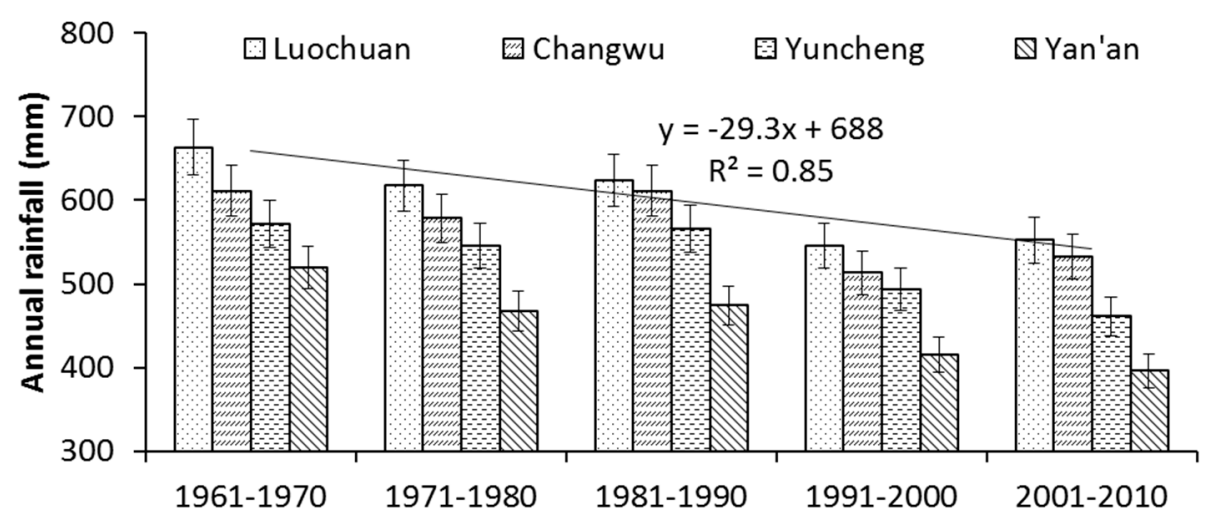

A: Comparison of annual rainfall
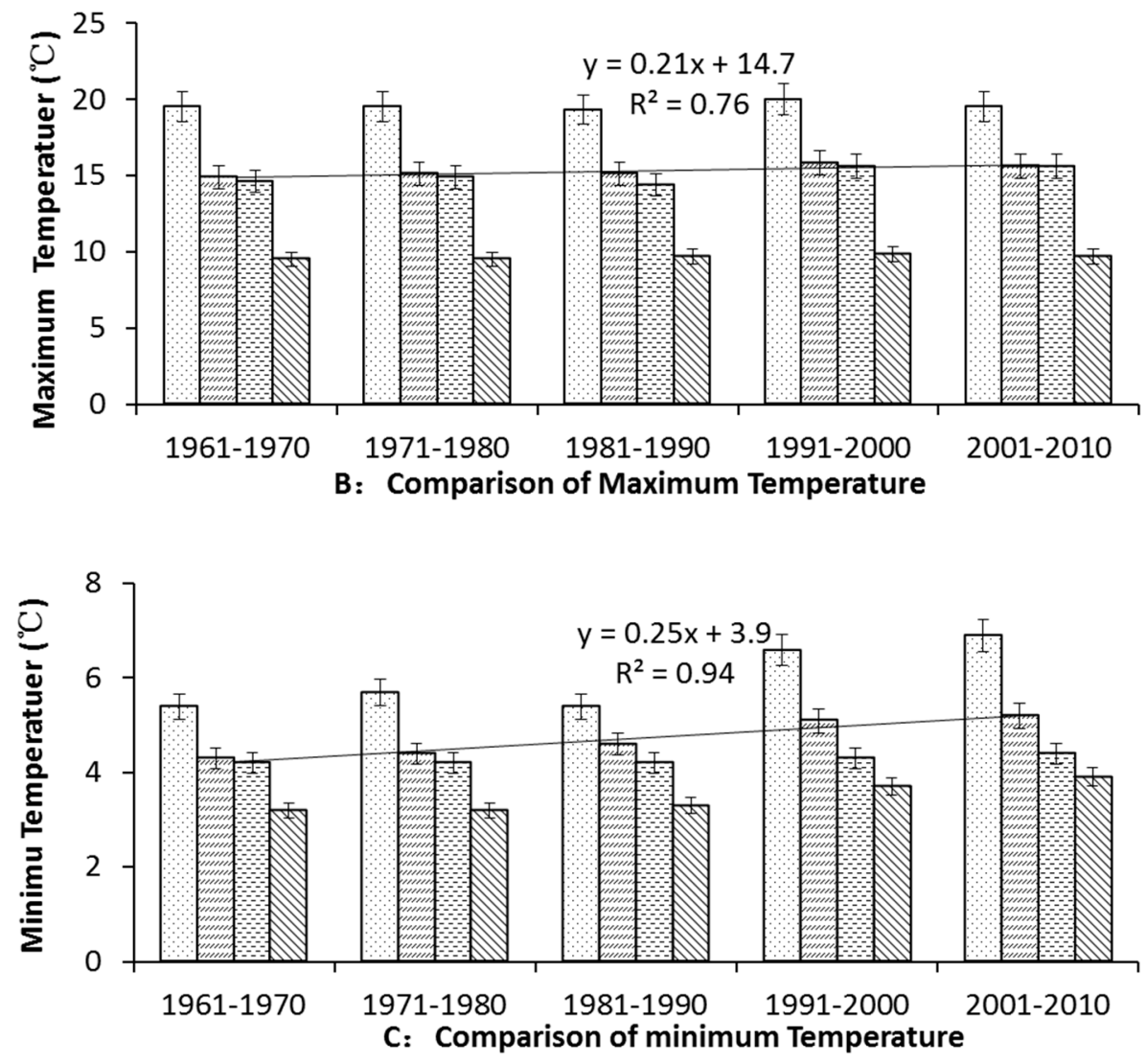

Figure 1. The variation of rainfall and temperature in different regions on the Loess Plateau of China from 1961 to 2010.

\subsection{Evaluation Results for the Environmental Policy Integrated Climate Model}

The RRMSE of monthly soil water was $14.0 \%, 12.0 \%, 12.0 \%, 13.0 \%$, and $6.0 \%$, respectively in $0-0.1 \mathrm{~m}, 0.1-0.5 \mathrm{~m}, 0.5-1.0 \mathrm{~m}, 1.0-1.5 \mathrm{~m}$, and 1.5-2.0 m soil layers, with an overall mean $M E$ value of 0.815 and a mean $R^{2}$ value of 0.824 . Compared with observed monthly soil water, simulated monthly soil water content was slightly higher, with $R E$ values of $0.0 \%, 1.6 \%, 6.4 \%, 5.3 \%$, and $0.5 \%$ respectively, but these differences were not significant $(p>0.05)$. Soil water content simulated by the EPIC model was similar to observed (Figure 2); the EPIC model can simulate soil water content in different soil depths well, and can simulate the monthly changing of soil water well in a winter wheat field in a semi-arid region. 

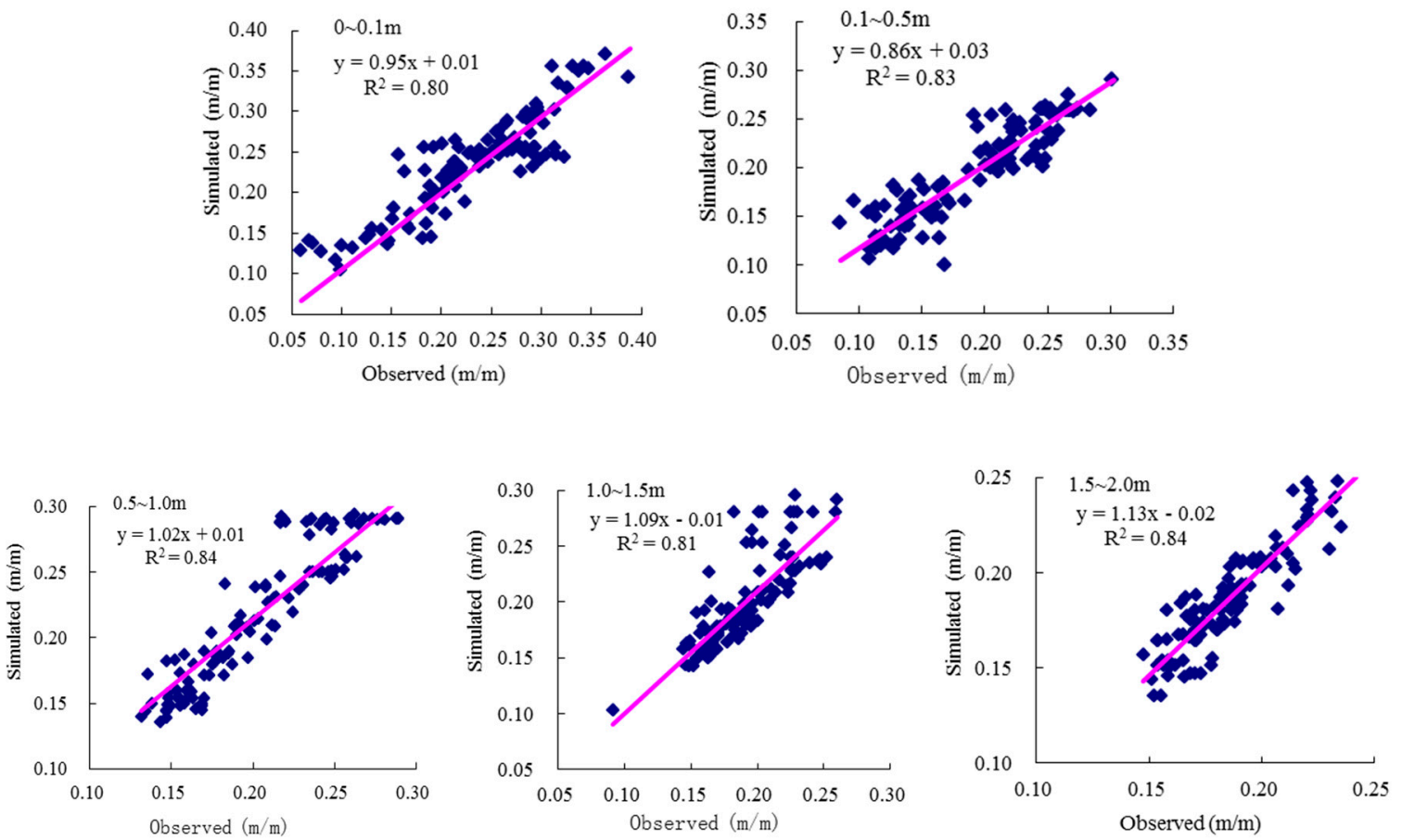

Figure 2. Comparison of simulated and measured soil-water content in different soil layers for the winter wheat cropping system at Changwu Agricultural Station.

From 1986 to 2000, the observed winter wheat yield was $3.90 \mathrm{t} / \mathrm{hm}^{2}$, with a standard deviation of $1.61 \mathrm{t} / \mathrm{hm}^{2}$, while the simulated yield was $3.84 \mathrm{t} / \mathrm{hm}^{2}$, with a standard deviation of $1.75 \mathrm{t} / \mathrm{hm}^{2}$. Two-tailed tests showed that there were no significant differences between the simulated and observed values $(p<0.05)$. The RMSE value between simulated and observed winter wheat yield was $0.291 \mathrm{t} / \mathrm{hm}^{2}$, while the values of $R^{2}$ and $M E$ were also nearly the same (Figure 3). These results indicated that simulated winter wheat yield was consistent with the observed yield. The EPIC model can calculate the impacts of climate change on winter wheat production in a semi-arid region.

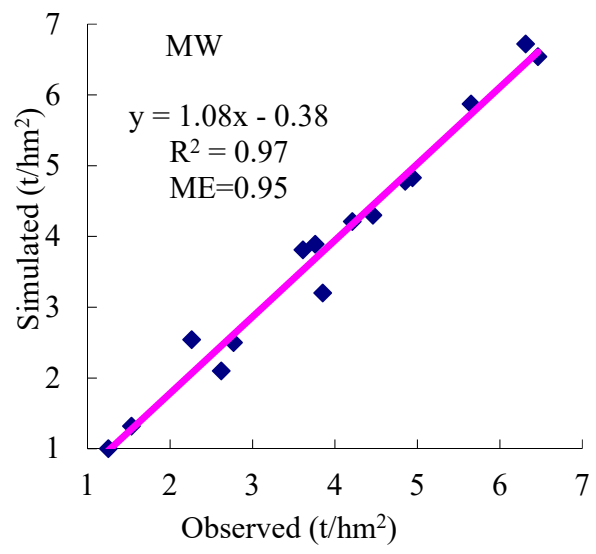

Figure 3. Comparison of simulated and measured grain yields of winter wheat at the Changwu Agricultural Station on the Loess Plateau of China.

\subsection{Response of Available Soil Water on Precipitation and Temperature}

Under the scenario that only precipitation changed (Figure 4A) from 1961 to 2010, the correlation coefficients between annual precipitation and available soil water in the winter wheat field were 0.89 , $0.92,0.83$, and 0.80 , respectively at Luochuan, Changwu, Yuncheng, and Yan'an. The areas' available 
soil water amounts in 0-4.0 m soil were 1445, 1295, 1067, and $1008 \mathrm{~mm}$, respectively, which were reduced by $14.0 \%, 19.0 \%, 20.1 \%$, and $16.0 \%$, respectively, compared with those during $1961-1970$.
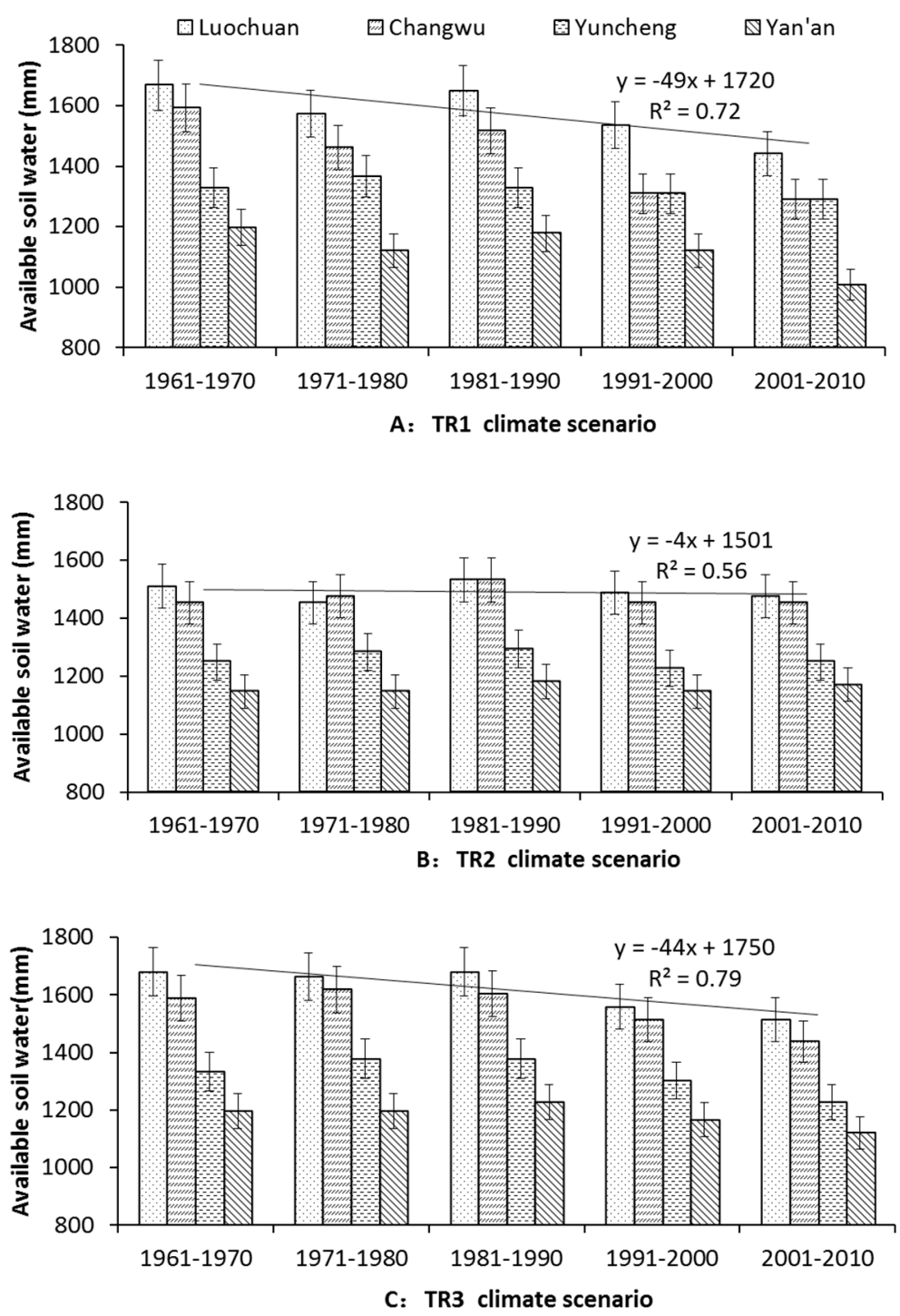

Figure 4. Response of available soil water on rainfall and temperature in a winter wheat field on the Loess Plateau of China from 1961 to 2010. TR1, TR2, and TR3 are climate scenarios from 1961 to 2010: TR1 means only precipitation changed, TR2 means only maximum temperatures changed, and TR3 means only minimum temperature changed.

In the scenario that only maximum temperature changed (Figure 4B) from 1961 to 2010, available soil water in the winter wheat field was slightly different in different years at Luochuan, Changwu, Yuncheng, and Yan'an, but the difference was not significant $(p>0.05)$. General, available soil water decreased slightly during warm years (1991-2000 and 2001-2010), while it increased slightly during cold years. Available soil water in 0-4.0 m soil was 1630, 1589, 1325, and $1215 \mathrm{~mm}$, respectively, at Luochuan, Changwu, Yuncheng, and Yan'an during 2001-2010, and decreased by 3.0\%, 2.0\%, 1.0\%, and $1.0 \%$, respectively, compared with the amounts during 1961-1970.

Under the scenario that only minimum temperature changed (Figure 4C) from 1961 to 2010, the correlation indices between available soil water and minimum temperature were $-0.72,-0.67$, -0.65 , and -0.64 , respectively, at Luochuan, Changwu, Yuncheng, and Yan'an. Available soil water in $0-4 \mathrm{~m}$ soil was $1507,1429,1225$, and $1118 \mathrm{~mm}$ respectively during 2001-2010, which decreased by 
$10.0 \%, 11.0 \%, 8.0 \%$, and $7.0 \%$, respectively, in comparison to $1961-1970$. These results indicated that the increase of the minimum temperature caused the decreasing of available soil water in winter wheat field in the semi-arid regions.

\subsection{Response of Soil Water Distribution on Precipitation and Temperature}

In the case of precipitation change only (TR1), and compared with 1961-1970, the soil water content of winter wheat field during 2001-2010 reduced $1.0-2.0 \%$ at the $2.5-3.5 \mathrm{~m}$ soil layer at Luochuan, $1.0-3.0 \%$ in the $1.5-3.5 \mathrm{~m}$ soil layer at Changwu, $1.0-3.0 \%$ in the $1.0-4.0 \mathrm{~m}$ soil layer at Yuncheng, and $1.0-4.0 \%$ in the $1.0-4.0 \mathrm{~m}$ soil layer at Yan'an. Rainfall decline causes the increase of soil water consumption in deep soil; the decreasing rate of soil water in deep soil increased gradually at Luochuan, Changwu, Yuncheng, and Yan'an.

In the case when maximum temperatures changed (TR2), and compared with 1961-1970, soil water content decreased by $0-1.0 \%$ at Luochuan, Changwu, Yuncheng, and Yan'an (Figure 5: TR2) during 2001-2010. The increase in maximum temperature led to a soil water reduction in 0-1.0 $\mathrm{m}$ soil. Compared with other areas, soil water was reduced the most at Luochuan.
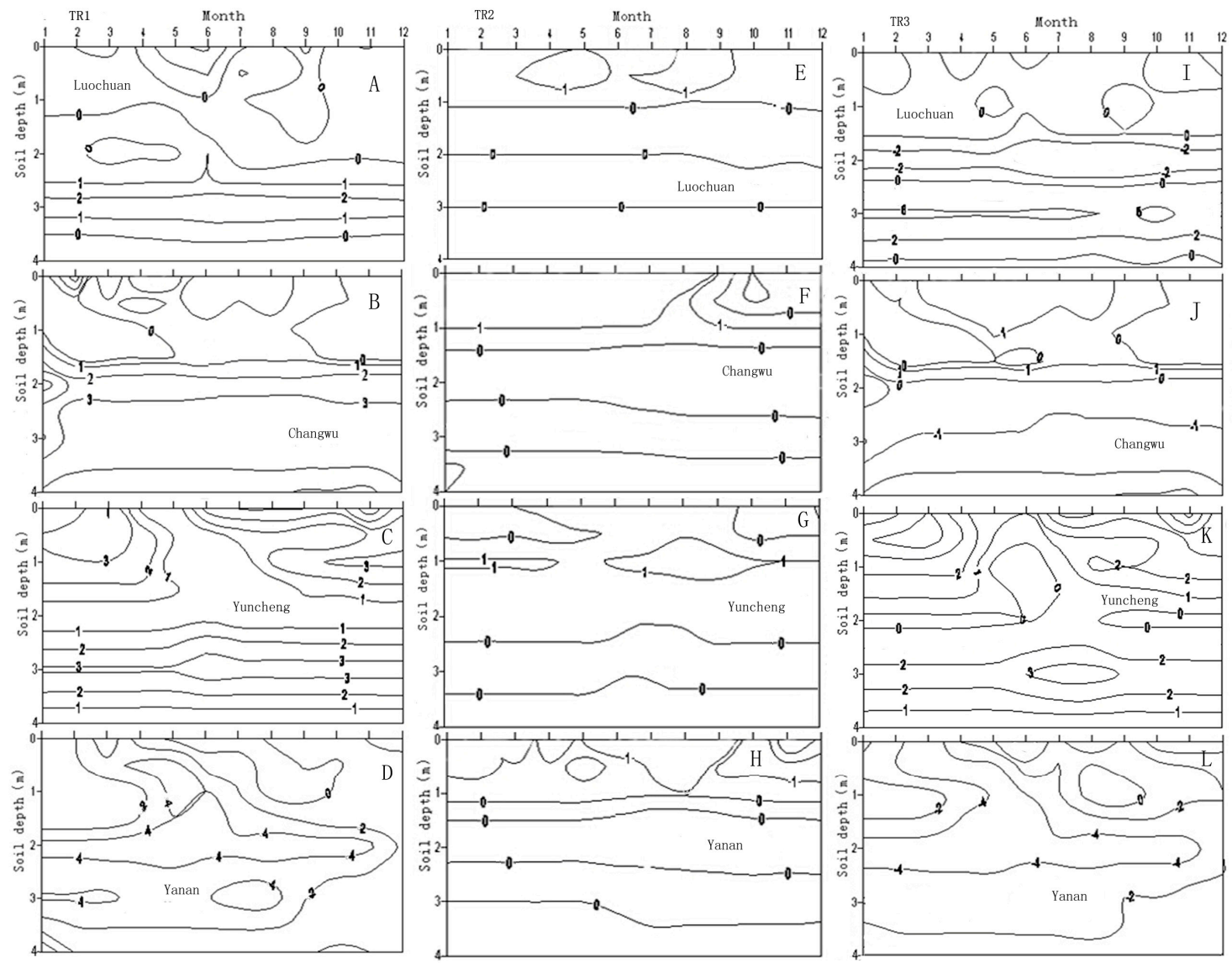

Figure 5. Compared with 1961-1970, soil water decrease from 2001-2010 in different soil layers in the winter wheat field on the Loess Plateau of China. (A-D) are at TR1 climate scenario; (E-H) are at TR2 climate scenario; (I-L) are at TR3 climate scenario. TR1 means only precipitation changed, TR2 means only maximum temperatures changed, andTR3 means only the minimum temperature changed.

In the case of a change in minimum temperature only (TR3), and compared with 1961-1970, the soil water content of winter wheat field during 2001-2010 decreased $0-2.0 \%$ at the $1.5-3.5 \mathrm{~m}$ soil layer at Luochuan, $0-3.0 \%$ in the $1.5-3.5 \mathrm{~m}$ soil layer at Changwu, $1.0-3.0 \%$ in the $1.0-4.0 \mathrm{~m}$ soil layer at Yuncheng, and $2.0-4.0 \%$ in the $1.0-4.0 \mathrm{~m}$ soil layer at Yan'an. 


\subsection{Response of Winter Wheat Yield to Precipitation and Temperature}

If just precipitation changed during 1961-2010 (TR1), the winter wheat yield performs a volatile downward trend. The average yield of winter wheat was $4.19,3.76,3.16$, and $2.50 \mathrm{t} / \mathrm{hm}^{2}$ in Luochuan, Changwu, Yuncheng, and Yan'an, respectively, during 2001-2010, which decreased by $8.5 \%, 7.6 \%$, $11.7 \%$, and $12.3 \%$, respectively, compared to 1961-1970. This result indicated that precipitation reduction is the main cause for the reduced yield of winter wheat on the Loess Plateau. In addition, the winter wheat yield at Yuncheng (in the semi-arid region) and Yan'an (arid region) were more sensitive to precipitation, compared with other areas.

If just the maximum temperatures changed during 1961-2010 (TR2), the yield trend of winter wheat is different in different climate zones on the Loess Plateau (Figure 6: TR2). Winter wheat yields were 3.86, 3.76, 3.49, and $3.14 \mathrm{t} / \mathrm{hm}^{2}$ at Luochuan, Changwu, Yuncheng, and Yan'an, respectively, during 2001-2010. Compared to 1961-1970, the winter wheat yield decreased by $6.4 \%, 6.8 \%$, and $7.2 \%$, respectively at Luochuan, Changwu, and Yuncheng, but increased by 3.0\% at Yan'an. These results indicated that maximum temperature rise produces a negative effect on winter wheat production at Luochuan (humid district), Changwu (semi-humid area), and Yuncheng (semi-arid region), while it is better to increase the winter wheat yield at Yan'an (arid region).
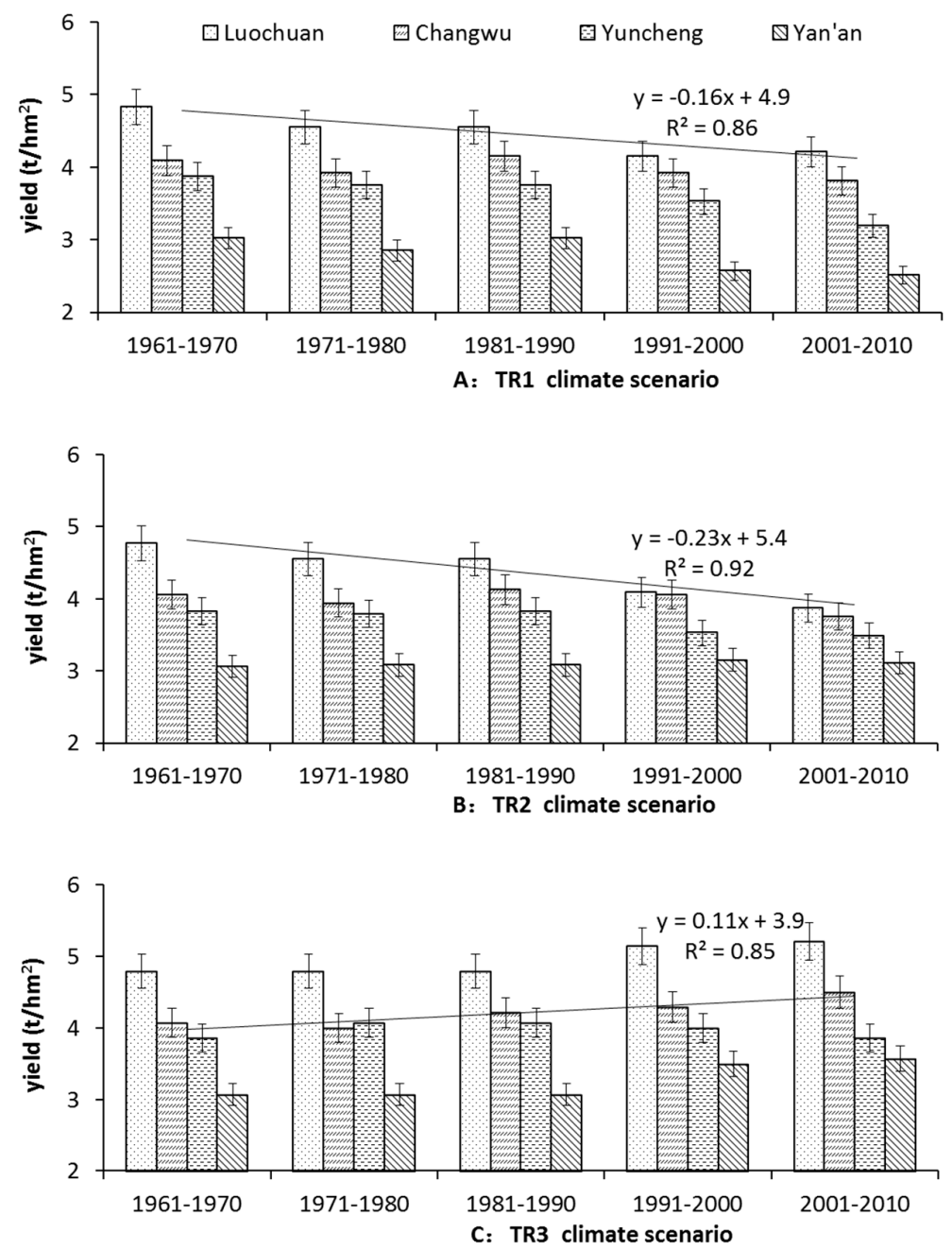

Figure 6. Response of winter wheat yield on precipitation and temperature on the Loess Plateau of China from 1961 to 2010. TR1 climate scenario means only precipitation changed, TR2 climate scenario means only maximum temperatures changed, and TR3 climate scenario means only minimum temperature changed. 
If just the minimum temperature changed during 1961-2010 (TR3), the yield of winter wheat performs an uptrend on the Loess Plateau (Figure 6: TR3). Winter wheat yields were 5.21, 4.52, 3.87, and $3.57 \mathrm{t} / \mathrm{hm}^{2}$, respectively at Luochuan, Changwu, Yuncheng, and Yan'an during 2001-2010, and increased by $8.8 \%, 10.2 \%, 1.5 \%$, and $12.0 \%$, respectively compared with $1961-1970$. The increasing of minimum temperature is better for increasing the winter wheat yield on the Loess Plateau of China.

\section{Discussions}

\subsection{Validation of the Environmental Policy Integrated Climate Model}

The EPIC model has been widely validated and applied around the world since it was published by the Black Land Research Center in Texas in 1984. Most studies suggested that the EPIC model can calculate annual yield for an average yield of winter wheat under different irrigation and fertilization management systems $[23,24]$, while numeral researchers report that EPIC models can simulate medium and average yield of winter wheat over a long period, but fail to reflect the changes of winter wheat yield between different years $[18,19]$. Results of EPIC model validation and application show that the EPIC model can simulate winter wheat yield in normal rainfall years in China [17,23,25]. Related research showed that the EPIC model has good adaptability for simulating crop yield and soil water change, not only on the Loess Plateau [17,23], but also at the North Plain of China [26-28]. This study showed that the EPIC model can accurately simulate winter wheat yield in the semi-arid land of the Loess Plateau, with an $R E$ value of $-1.5 \%$. Williams pointed out that calibration and validation of the accuracy of the EPIC model are necessary for its application $[15,16]$. In this study, we used long-term experimental data, including soil data, crop data, and weather data, to calibrate and validate the EPIC model; these works provide one good base for the accuracy of simulation results. Validation results showed that the values of $R^{2}$ and $M E$ were 0.97 and 0.95 , respectively. Simulated winter wheat yield can reflect the annual variability in dry land winter wheat on the Loess Plateau of China.

The validation results of [29] show that the EPIC model can simulate soil water content in the dry land field, and Zhang et al. [29] also use the EPIC model to simulate the dynamic changing of soil water in 0-2.0 m soil for different cropping system. This study shows that the EPIC model simulated soil water content well in 0-2.0 m soil, with an RRMSE value of $6.0-14.0 \%$. A few related studies indicate that the EPIC model did not simulate soil water well in very dry and wet seasons $[25,27]$. Shallow soil water content, affected by precipitation and crop consumption, are particularly vulnerable to the effects of precipitation on dry land. This study shows that the simulation results of soil water content in $0-0.5 \mathrm{~m}$ soil were less accurate than those in $0.5-2.0 \mathrm{~m}$ soil.

\subsection{Response of Soil Water in a Winter Wheat Field to Precipitation and Temperature}

Based on the analysis of soil water and weather data at Gansu Province, Pu et al. [7] pointed out that when impacted by rainfall decreasing, soil water content performed a downtrend trend in dry land fields during 1971-2000. Soil water in 0-2 $\mathrm{m}$ soil decreased 40-90 $\mathrm{mm}$ during spring and autumn, and 20-36 mm during the summer in the winter wheat dry land field [7,16]. Yang et al. [30] report that soil water decreased more in the winter wheat field during spring compared to other seasons. This study shows that in the case of only precipitation changing, soil water in 0-4 m soil decreased $247 \mathrm{~mm}$, $109 \mathrm{~mm}, 131 \mathrm{~mm}$, and $124 \mathrm{~mm}$ (Figure 4: TR1) at Luochuan, Changwu, Yuncheng, and Changwu, respectively during 2001-2010, compared the amounts during 1961-1970. In addition, this study also shows that decreases in soil water were mainly concentrated in the $1.0-4.0 \mathrm{~m}$ soil layer; a decrease in rainfall caused greater consumption of deep soil water in winter and spring seasons.

Precipitation and evaporation both are important meteorological factors that affect soil water content. Temperature is also a meteorological factor that affects soil water content indirectly, through its impacts on evaporation. Generally, there was a negative correlation between soil water content and temperature, while there was a positive correlation between soil water and precipitation. Related research has reported that variations in temperature accounts for more than $6.7 \%$ of the soil water 
change on the Loess Plateau of China [31,32] and other semi-arid regions in the world [33]. Therefore, besides precipitation, temperature is also one of the important factors for influencing soil water in dry land winter wheat fields. This research shows that the rise of maximum temperature results in a decrease of soil water (1.0-3.0\%); the rise of minimum temperature causes the decreasing of soil water (7.0-11.0\%) in winter wheat fields on the Loess Plateau. Li et al. [34] report that excessive use of fertilizer makes crops consume more deep soil water, which causes the soil desiccation of high-yielding winter wheat fields on the Loess Plateau. This study showed that soil water in 0-1.0 m soil decreased $0-1.0 \%$, due to the rise of maximum temperature; minimum temperature increases caused a reduction of $1.0-4.0 \%$ in the $1.0-3.0 \mathrm{~m}$ soil in winter wheat fields on the Loess Plateau. Therefore, besides the excessive use of fertilizer, a decrease in precipitation and increase in minimum temperatures are also important factors that cause an increase in soil water depletion in the deep soil in dry land winter wheat fields.

\subsection{Response of Winter Wheat Yield to Precipitation and Temperature}

This study showed that under scenario TR1 and compared with 1961-1970, winter wheat yield decreased $8.5 \%, 7.6 \%, 11.7 \%$, and $12.3 \%$, respectively, at Luochuanm, Changwu, Yuncheng, and Yan'an during 2001-2010. Low temperatures are not better for the growth of winter wheat, and too-low temperatures often lead winter wheat to die from chilling stress during the winter season. A rise in temperature leads to less death of winter wheat and greater consumption of soil water during the winter seasons $[35,36]$. Warm weather makes the winter wheat growth period appear earlier and leads to the overwintering stage being significantly reduced [36,37]. Based on simulation results of winter and spring wheat for more than 80 locations in North China, Wang et al. [38] pointed out, without considering the factors of agricultural technology. Radiation fluctuations are the main factors for the variation of winter wheat yields in different years during 1961-2005; the decrease of chill stress for winter wheat increased the winter wheat yield on the Loess Plateau. This study shows that under scenario TR2 and compared with 1961-1970, the winter wheat yield decreased by $6.4 \%, 6.8 \%$, and $7.2 \%$ at Luochuan, Changwu, and Yuncheng, respectively, but increased 3.0\% at Yan'an during 2001-2010. Under scenario TR3, and compared with 1961-1970, the winter wheat yield increased 8.8\%, 10.2\%, $1.5 \%$, and $12.0 \%$ at Luochuan, Changwu, Yuncheng, and Yan'an, respectively. Overall, maximum temperature rise is detrimental to yield increase, while minimum temperature rise is better to increase the yield of winter wheat on the Loess Plateau of China.

\section{Conclusions}

Though the accuracy of simulated soil water in $0-0.5 \mathrm{~m}$ soil was slightly low, the EPIC model can simulate the dynamic change of soil water in winter wheat field on the Loess Plateau of China. A decrease in precipitation decreased the soil water in 0-0.4 $\mathrm{m}$ soil at Luochuan, Changwu, Yuncheng, and Yan'an in winter wheat fields. Increasing the maximum temperature causes soil water in 0-1.0 m soil to decrease between $0-1.0 \%$, while the increase of minimum temperature leads soil water in $1.0-3.0 \mathrm{~m}$ soil to decreased by $1-4.0 \%$ in winter wheat fields on the Loess Plateau. A reduction in rainfall leads to a winter wheat yield decrease of $7.6-12.3 \%$ at Luochuan, Changwu, Yuncheng, and Yan'an. The increase of maximum temperature causes the reduction of winter wheat yield (3.0-7.2\%), while the increase of minimum temperature leads to a winter wheat yield increase $1.5-12.0 \%$ on the Loess Plateau of China.

Author Contributions: X.W. analyzed the data and wrote the paper; M.Q. analyzed the data and helped to write the paper; Y.H. proposed the ideas and designed the experiments with G.Y.; and F.R. reviewed the paper.

Funding: This study was sponsored by the National Key Research and Development Program of China (No. 2016YFD0300210) the international cooperation projects of Sichuan Province (No. 2018HH0039) and the Foundation of Southwest University of Science and Technology University for new teachers with doctoral degrees (No. 11zx7140).

Conflicts of Interest: The authors declare no conflict of interest. 


\section{References}

1. Liu, B.; Shao, M.A. Estimation of soil water storage using temporal stability in four land uses over 10 years on the Loess Plateau, China. J. Hydrol. 2014, 517, 974-984. [CrossRef]

2. Dong, J.G.; Shen, C.C.; Kong, X.G.; Wang, H.C.; Jiang, X.Y. Reconciliation of hydroclimate sequences from the Chinese Loess Plateau and low-latitude East Asian summer monsoon regions over the past 14,500 years. Palaeogeogr. Palaeoclimatol. Palaeoecol. 2015, 435, 127-135. [CrossRef]

3. Liu, W.Z.; Zhang, X.C.; Dang, T.H.; Zhu, O.Y.; Li, Z.; Wang, J.; Wang, R. Soil water dynamics and deep soil recharge in a record wet year in the southern Loess Plateau of China. Agric. Water Manag. 2010, 97, 1133-1138. [CrossRef]

4. Li, X.Y.; Gong, J.D.; Gao, Q.Z.; Li, F.R. Incorporation of ridge and furrow method of rainfall harvesting with mulching for crop production under semiarid conditions. Agric. Water Manag. 2001, 50, 173-183. [CrossRef]

5. Su, Z.Y.; Zhang, J.S.; Wu, W.L.; Cai, D.X.; Lv, J.J.; Jiang, G.H.; Huang, J.; Gao, J.; Hartmann, R.; Gabriels, D. Effects of conservation tillage practices on winter wheat water-use efficiency and crop yield on the Loess Plateau, China. Agric. Water Manag. 2007, 87, 307-314. [CrossRef]

6. Liu, Z.J.; Chen, Z.J.; Ma, P.Y.; Meng, Y.; Zhou, J.B. Effects of tillage, mulching and N management on yield, water productivity, $\mathrm{N}$ uptake and residual soil nitrate in a long-term wheat-summer maize cropping system. Field Crops Res. 2017, 213, 154-164. [CrossRef]

7. Pu, J.Y.; Yao, X.Y.; Den, Z.Y. Impact of Climatic Change on Soil Water Content in Loess Plateau, Gansu. Chin. J. Soil Sci. 2006, 37, 1086-1090.

8. Peng, S.Z.; Ding, Y.X.; Wen, Z.M.; Chen, Y.M.; Cao, Y.; Ren, J.Y. Spatiotemporal change and trend analysis of potential evapotranspiration over the Loess Plateau of China during 2011-2100. Agric. For. Meteorol. 2017, 233, 183-194. [CrossRef]

9. Li, C.; Wu, P.T.; Li, X.L.; Zhou, T.W.; Sun, S.K.; Wang, Y.B.; Luan, X.B.; Yu, X. Spatial and temporal evolution of climatic factors and its impacts on potential evapotranspiration in Loess Plateau of Northern Shaanxi, China. Sci. Total Environ. 2017, 589, 165-172. [CrossRef] [PubMed]

10. Sun, W.Y.; Mu, X.M.; Song, X.Y.; Wu, D.; Cheng, A.F.; Qiu, B. Changes in extreme temperature and precipitation events in the Loess Plateau (China) during 1960-2013 under global warming. Atmos. Res. 2016, 168, 33-48. [CrossRef]

11. Wan, X.; Wang, R.Y.; Li, Z.Y. Variation characters of agrometeorological elements in Loess Plateau of East Gansu. Chin. J. Ecol. 2007, 3, 344-347, (In Chinese with English Abstract).

12. Yan, J.P.; Zhang, H.J.; Jiang, Y.X. Response of Climate Productivity to Change Climate at County Level in the Hilly-gully Regions in the Loess Plateau-A Case Study in Mizhi County, North Shaanxi Province. Arid Zone Res. 2008, 25, 59-63, (In Chinese with English Abstract). [CrossRef]

13. Tesfaye, S.; Birhane, E.; Leijnse, T.; Vander, Z.S.E. Climatic controls of ecohydrological responses in the highlands of northern Ethiopia. Sci. Total Environ. 2017, 609, 77-91. [CrossRef] [PubMed]

14. Er, Y.H.; Shi, Q.; Ma, Y.P. The impacts of future climatic change on agricultures and eco-environment of Loess Plateau in next decade. Acta Ecol. Sin. 2011, 31, 5542-5552, (In Chinese with English Abstract).

15. Williams, J.R.; Jones, C.A.; Dyke, P.T. A modeling approach to determining the relationship between erosion and soil productivity. Trans. ASAE 1984, 27, 129-144. [CrossRef]

16. Williams, J.R.; Jones, C.A.; Kiniry, J.R. The EPIC Crop Growth Model. Trans. ASAE 1989, 32, $497-511$. [CrossRef]

17. Wang, X.C.; Li, J.; Muhammad, N.T.; Fang, X.Y. Validation of the EPIC model and its utilization to research the sustainable recovery of soil desiccation after alfalfa (Medicago sativa L.) by grain crop rotation system in the semi-humid region of the Loess Plateau. Agric. Ecosyst. Environ. 2012, 161, 152-160. [CrossRef]

18. Stockle, C.O.; Dyke, P.T.; Williams, J.R.; Stockle, C.O.; Dyke, P.T.; Williams, J.R.; Jones, A.; Norman, J.R. A method for estimating the direct and climatic effects of rising atmospheric carbon dioxide on growth and yield of crops: Part II-Sensitivity analysis at three sites in the Midwestern USA. Agric. Syst. 1992, 38, 239-256. [CrossRef]

19. Stockle, C.O.; Dyke, P.T.; Williams, J.R.; Jones, A.; Norman, J.R. A method for estimating the direct and climatic effects of rising atmospheric carbon dioxide on growth and yield of crops: Part I-Modification of the EPIC model for climate change analysis. Agric. Syst. 1992, 38, 225-238. [CrossRef] 
20. Izaurralde, R.; Williams, J.R.; Mcgill, W. Modeling Soil Organic Carbon Changes in CRP Land and a Long Term Crop Rotation Trial with EPIC; Joint Global Change Research Institute: College Park, MD, USA, 2004; pp. 108-196.

21. Bennie, A.T.P.; Taylor, H.M.; Georgen, P.G. An assessment of the core-break method for estimating root density of different crops in the field. Soil Tillage Res. 1987, 9, 343-347. [CrossRef]

22. Blake, G.R.; Hartge, K.H. Bulk density. In Methods of Soil Analysis. Part I. Physical and Mineralogical Methods, 2nd ed.; Klute, A., Ed.; Agronomy 9; American Society of Agronomy: Madison, WI, USA, 1986; pp. $363-382$.

23. Wang, X.C.; Li, J. Evaluation of crop yield and soil water estimates using the EPIC model for the Loess Plateau of China. Math. Comput. Model. 2010, 51, 1390-1397. [CrossRef]

24. Worou, O.N.; Gaiser, T.; Saito, K.; Goldbach, H.; Ewert, F. Simulation of soil water dynamics and rice crop growth as affected by bunding and fertilizer application in inland valley systems of West Africa. Agric. Ecosyst. Environ. 2012, 162, 24-35. [CrossRef]

25. Lu, C.H.; Ittersum, M.K.; Rabbinge, R. Quantitative assessment of resource-use efficient cropping systems. A case study for Ansai in the Loess Plateau of China. Eur. J. Agron. 2003, 19, 311-326. [CrossRef]

26. Zhao, X.N.; Hu, K.L.; Stahr, K. Simulation of SOC content and storage under different irrigation, fertilization and tillage conditions using EPIC model in the North China Plain. Soil Tillage Res. 2013, 130, 128-135. [CrossRef]

27. Wang, X.P.; Huang, G.H.; Yang, J.S.; Huang, Q.Z.; Liu, H.J.; Yu, L.P. An assessment of irrigation practices: Sprinkler irrigation of winter wheat in the North China Plain. Agric. Water Manag. 2015, 159, $197-208$. [CrossRef]

28. Qiao, J.M.; Yu, D.Y.; Wu, J.G. How do climatic and management factors affect agricultural ecosystem services. A case study in the agro-pastoral transitional zone of northern China. Sci. Total Environ. 2018, 614, 314-323. [CrossRef] [PubMed]

29. Zhang, Y.J.; Li, J.; Guo, Z.; Yue, Z.F. Long-Term Simulation of Winter Wheat Yield and Soil Water Response to Conservation Tillage Rotation in Weibei Highland. Sci. Agric. Sin. 2015, 48, 2730-2746.

30. Yang, X.L. Evolution of Soil Moisture and Its Response to Climate Change in Longdong Loess Plateau. J. Desert Res. 2009, 2, 305-311.

31. Yu, T.; He, Y.B.; Duan, X.Q.; Zou, Z.Q.; Lin, L.R.; Chen, J.J. Preferential flows and soil moistures on a Benggang slope: Determined by the water and temperature comonitoring. J. Hydrol. 2017, 553, 678-690.

32. Zhang, B.; Zhang, T.F. Responses of reference crop evapotranspiration in Loess Plateau of Northwest China to climate change in 1961-2010 and estimation of a future trend. Chin. J. Ecol. 2013, 32, 733-740.

33. David, C.N.; Merle, F.V. Water use and environmental parameters influence proso millet yield. Field Crops Res. 2017, 212, 34-44.

34. Li, J.; Chen, B.; Li, X.F. Effects of deep soil desiccations on alfalfa grasslands in different rainfall areas of the Loess Plateau of China. Acta Ecol. Sin. 2007, 27, 75-89.

35. Marcin, R.; Barbara, J.; Monika, S. Deacclimation may be crucial for winter survival of cereals under warming climate. Plant Sci. 2017, 256, 5-15.

36. Romulo, P.L.; Jeffrey, T.E.; Tyson, E.O. Meteorological limits to winter wheat productivity in the U.S. southern Great Plains. Field Crops Res. 2017, 203, 212-226.

37. Fang, Q.; Zhang, X.Y.; Chen, S.Y.; Shao, L.W.; Sun, H.Y. Selecting traits to increase winter wheat yield under climate change in the North China Plain. Field Crops Res. 2017, 207, 30-41. [CrossRef]

38. Wang, Z.Q.; Fang, W.H.; He, F. Effect of climate change on wheat yield in northern China. A research based on EPIC model. J. Nat. Disasters 2008, 17, 109-114.

(C) 2018 by the authors. Licensee MDPI, Basel, Switzerland. This article is an open access article distributed under the terms and conditions of the Creative Commons Attribution (CC BY) license (http://creativecommons.org/licenses/by/4.0/). 